\title{
Research on Teaching Reform of Mechanical and Electronic Specialty Based on Robot Education
}

\author{
Xingzhi Xu \\ College of Mechanical and Control Engineering, Guilin University of Technology, Guilin, China \\ Email: 414246895@qq.com
}

How to cite this paper: Xu, X.Z. (2021) Research on Teaching Reform of Mechanical and Electronic Specialty Based on Robot Education. Open Access Library Journal, 8: e7741.

https://doi.org/10.4236/oalib.1107741

Received: July 8, 2021

Accepted: July 26, 2021

Published: July 29, 2021

Copyright $\odot 2021$ by author(s) and Open Access Library Inc.

This work is licensed under the Creative Commons Attribution International License (CC BY 4.0).

http://creativecommons.org/licenses/by/4.0/

\section{(c) (i) Open Access}

\begin{abstract}
Mechanical electronic technology represented by robot technology is very important in many fields such as military, civilian and extensive application, how under the new era, combined with the current development status and trend of scientific, complete mechanical and electrical professional teaching is very important, the article analyses the core technology of the robot and finds the combining site of robot technology and teaching and research. By using the method of higher education psychology, this paper analyzes the learning characteristics and psychological characteristics of college students, and puts forward that robot education should be deeply applied to the teaching of mechanical and electronic engineering specialty, and that robot technology should be deeply combined with mechanical and electronic specialty education, so as to improve the undergraduate mechanical and electronic specialty education learning initiative and efficiency.
\end{abstract}

\section{Subject Areas}

Mechanical Engineering

\section{Keywords}

Machinery and Electronics, Robotics, The Teaching Reform

\section{Introduction}

Mechanical and electronic engineering is an interdisciplinary discipline of mechanical engineering and automation. Robotics is an important research direction of mechanical and electronic specialty. It is an interdisciplinary product, including automatic control, servo motor control, sensor technology and so on. 
Robotics has important application value in many fields, and industrial robotics is the most widely used at present. 1) In all kinds of factory palletizing, highly automated robots are widely used. Handling robot can carry out efficient sorting and handling according to the characteristics of carrying objects, as well as the place where the objects are classified, on the basis of keeping the shape and the nature of the objects unchanged, so that the packing equipment can complete the task of hundreds of blocks of stacking per hour. In the production line loading and unloading, container handling and other aspects play a very important role. 2) Welding robot mainly undertakes welding work, different industrial types have different industrial needs, so the common welding robot has spot welding robot, arc welding robot, laser robot and so on. Automobile manufacturing industry is the most widely used welding robot industry, in the difficulty of welding, welding quantity, welding quality and other aspects has an incomparable advantage of manual welding. 3) The research and development of the assembly robot combines a variety of technologies, including communication technology, automatic control, optical principle, micro-electronic technology, etc. R \& D personnel according to the assembly process, write the appropriate program, applied to the specific assembly work. Because the assembly work is complex and delicate, we choose the assembly robot to carry out the installation of electronic parts and automobile fine parts. 4) Robots have multi-dimensional additional functions. It can replace the work of the staff in the special post, such as in the high-risk areas such as nuclear contaminated areas, toxic areas, nuclear contaminated areas, high-risk unknown areas to detect. There are also places that humans cannot specifically reach, such as the detection of sick patients, the detection of industrial defects, the detection of life in earthquake relief sites, and so on. The robot includes servo motor, reducer and high precision numerical control system. These three aspects determine the complexity of the task that the robot can complete, which is also the hot spot of robot research at home and abroad.

\section{Analysis of the Present Situation of Robot Education in Mechanical and Electronic Engineering Teaching Research}

Robot technology is an important development field of machinery and electronics engineering discipline, in industry, military, civil and other fields, the robot is playing a more and more important role, this paper mainly analyzes robot technology to the mechanical electronic engineering teaching, and analyze the trend of the development of robot technology and in the important role of education, major in mechanical or electrical engineering. Robot is a kind of automation technology, which can be programmed to perform certain tasks without human intervention, that is to say, a robot can accept human instructions, and then finish the execution autonomously. Robot is one of the forms of artificial intelligence. This is shown in Figure 1, since 1997, the RoboCup competition, which 


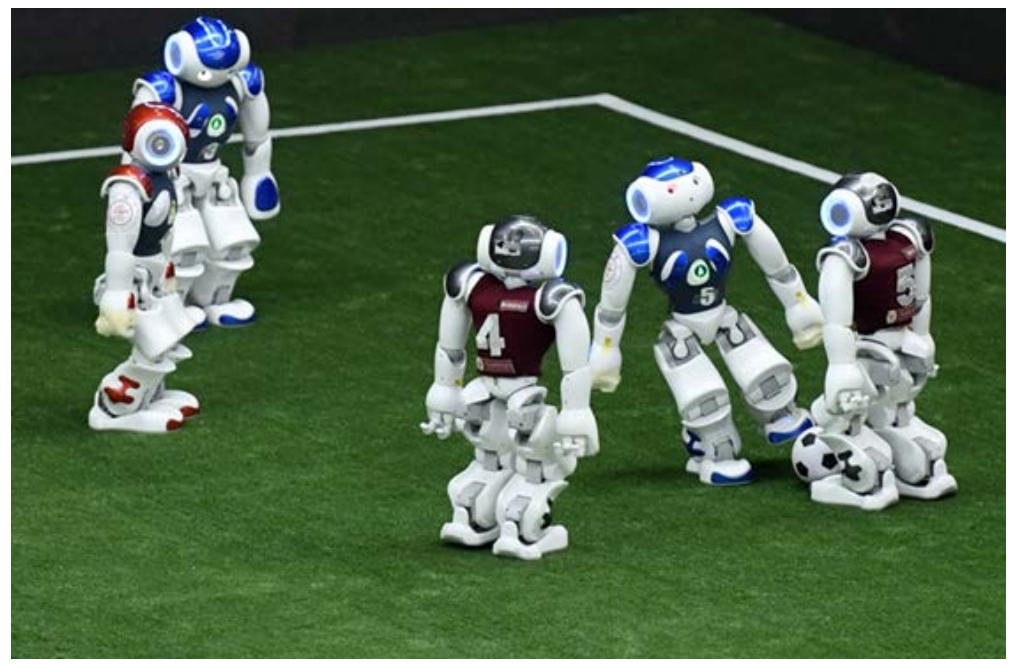

Figure 1. RoboCup competition.

originated from academic research, has gradually exerted a growing influence on university engineering education. At present, the competition is the most authoritative robot competition in the global robotics academic field. The Junior Robot World Cup, which began in 2000, has also begun to have a profound impact on technical education in primary and secondary schools. In 2013, the World Association for Robotics in Education launched the World Competition for Robotics in Education.

Robots are bound to be the most important production tool in the "smart factory" of the future. At present, robots can be seen in aerospace, pharmaceutical, mechanical processing, parts production and assembly and other fields. In China, high-end robots are basically monopolized by Europe, Japan and other countries, especially in the core technology of robots. The three core technologies of robots include reducer, servo motor and numerical control system, which account for almost $80 \%$ of the cost of robots. At the same time, due to the robot application environment is complex, uncertain, and even change, the precise localization of robot end position and control is of great importance in many application scenarios, the end of the mechanical arm is movement, under the predefined trajectory can only complete the predetermined simple production tasks. In order to make the robot complete a series of complex production operations in complex environment, the precise guidance technology of its terminal is very important. Therefore, in the teaching process, it is necessary to analyze the difficult problems of current robot technology. As shown in Figure 2, two types of robots in complex environment are used in the robot teaching process. In Figure 2(a), the complex environment presented is the CNC machine tool processing scene based on the automatic manipulator, in which the high-precision CNC system of the multi-joint manipulator is the core of the whole robot system. The principle of numerical control system is introduced to students, and they are guided to develop simple numerical control system by themselves. In Figure 2(b), the complex environment presented is that the real human settlement environment 


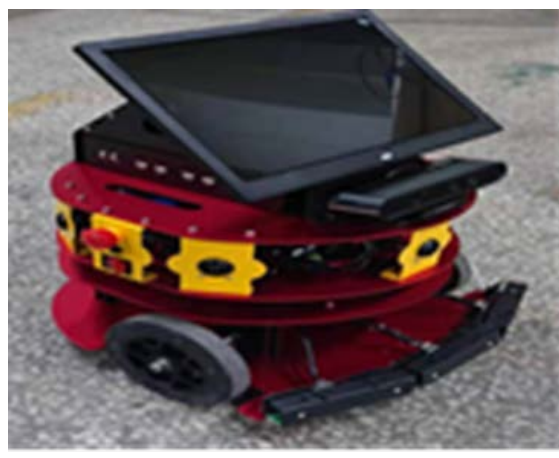

(a)

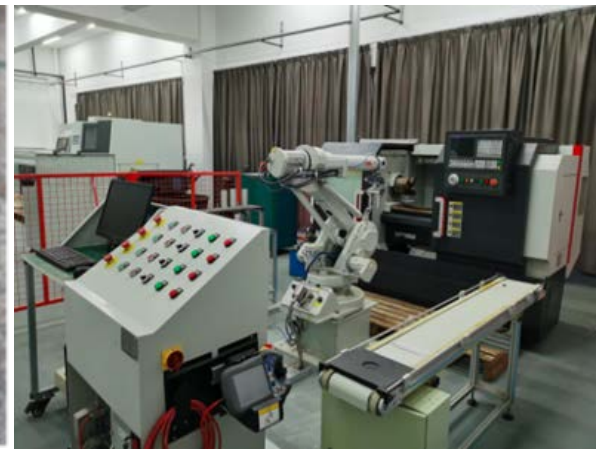

(b)

Figure 2. Two types of complex environment robots used in robotics teaching. (a) CNC machine manipulator; (b) service robot.

is a dynamic and unstructured complex environment, in which the precise guidance technology of the robotic arm end based on multi-sensor information fusion is the core technology of the robot system. To complete complex tasks, the robot must have the perception ability of the external environment. The guidance technology based on multi-sensor is to improve the intelligence level of the robot by using sensors such as vision and inertia.

Robotics teaching began to sprout in 1989 , and now it has entered the late stage of the formation of a new discipline. In the early stage of growth, educational robotics will begin to usher in the rapid development of theory. In China, there are many educational robot competitions, mainly including Robomasters Robot Competition, Asia Pacific Flying Robot Competition and so on. In the summer of 2013, the Robomasters National Collegiate Robotics Competition made its first attempt, with the theme of "visual automatic recognition of moving target throwing". In the summer of 2014, the Robomasters National Collegiate Robotics Competition underwent a comprehensive upgrade. The initial format of the competition was for teams to build multiple vehicles and compete against each other on a complex field, with the winners and winners determined by an electronic referee system. More than 1000 students from more than 35 universities across the country applied, and 98 were selected. As the world's first robot competition combining engineering technology and viewing value, it requires competitors to comprehensively master the chassis, cradle head, launching mechanism, motor drive and other technologies, which has set off a new scientific research frenzy among universities. From June to August 2016, Robomasters added new battlefield elements such as Hero Robots, Nine-Grid Gains, and Resource Island, which put forward new requirements for robotic landing mechanical design, robotic arm grabbing, and machine vision, attracting 228 teams from more than 160 universities around the world. Nearly 7000 young engineers signed up for the competition [1].

RoboMasters is divided into two events: Robot Challenge and Technical Challenge. Engineering robots have been added to combat matches, which can transport ammunition, assist hero robots to land on the island, pave the gullies, and 
add health and other skills. At the same time, various kinds of guidance lines will be laid in the field, which can be used by the aerial robots to set the position and complete more complex and precise technical movements. The technical challenge is divided into two types of robot challenges on the ground and in the air. The competition will test the comprehensive level of technical points in the form of robots completing tasks fully automated. As shown in Figure 3, the makeup photos of our robot in the RoboMasters Competition.

RoboMasters robot competition is the core content inspects the student to the machine vision, the control system research and development ability, and these two technologies is the core content in robotics, from the perspective of education psychology, can mobilize students' learning enthusiasm, and can be combined with the current technology development trend, to guide the students to participate in scientific research. Robomasters requires the robot to be able to automatically aim at the target and track the target. Image recognition and tracking system has important application value in many fields and is a research hotspot at home and abroad. There are many research achievements and methods in image detection and tracking. Literature [2] and [3] studied the detection and tracking of targets, and the integral graph obtained by summing pixel gray values in the oblique downward direction was used for rapid feature comparison and significantly improved the processing speed. Literature [4] adopts Lucas-Kanade pyramid optical flow algorithm to realize feature matching through simple calculation of cross-relation number or sum of squares of gray difference. The area that deviates from the motion model due to parallax or the moving target is the outer point (false match), and all matches are filtered out to exclude points. Literature [5] and [6] adopted the most commonly used Random Sample Consensus (RANSAC) [7] algorithm to remove the exclusion points and describe the characteristic displacement vectors between two frames to form the corresponding vector data. Li Wanyi [8] performed model fitting for these data. If too few points accurately fit the transformation model, the control point estimation model would be re-selected.

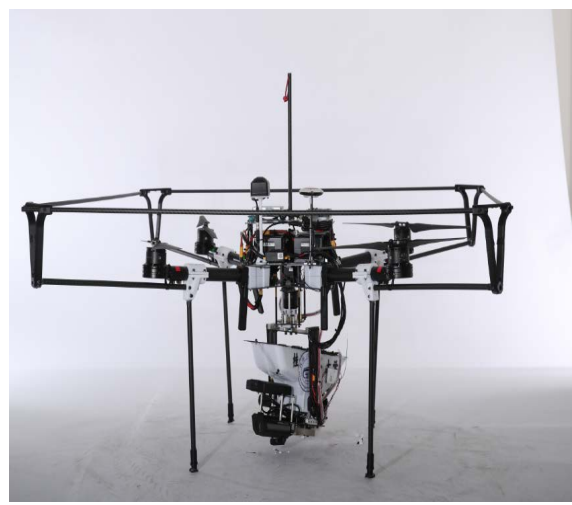

(a)

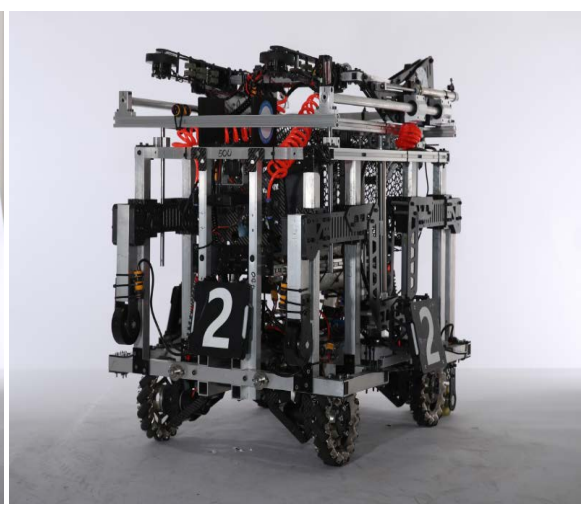

(b)

Figure 3. The makeup photo of our robot in the Robomasters competition. (a) Hero robot; (b) Cruising robot. 


\section{The Relationship between College Students' Psychological Characteristics and Robot Teaching}

In the psychology of higher education, it is necessary to combine the psychological characteristics and learning characteristics of college students in teaching. The basic cognitive characteristic of college students is that their observation power has developed to not only observe the surface features of things, but also to grasp the essence of things from the outside to the inside. They can observe things accurately, meticulously and profoundly, and their arbitrariness and comprehensiveness have been greatly strengthened. Because robots are made up of multiple complex systems, including control system, visual system, intelligent decisionmaking system, etc. In each system, there are various aspects of knowledge. Combined with the cognitive ability of college students to the essence of things, college students can analyze and research the basic principles and algorithms inside the system. Such as how to realize the position and posture of the robot to accurately measure, to research the robot positioning technology will need to research the technology of inertial navigation, GNSS navigation, visual, the students will go to study and research of inertial navigation technology, inertial measurement unit is measuring target current stance, including line motion, angular motion, etc., Describes the current various forms of an object, and transmits the collected data to the navigation computer through the circuit. The navigation computer is the brain of the whole system. The main source of the inertial measurement signal is the data generated by the gyroscope and accelerometer. In addition, there is the need for the magnetometer to calibrate in general direction. The navigation computer needs to put the data received into the software for calculation. The calculation has two tasks: the first is to record the coordinate system of the current target; the second is to calculate the attitude of the current next state, so as to provide parameters for the positioning parameters of the target and its navigation calibration. Inertial devices can be divided into platform and strapdown. At present, the navigation method combining inertial navigation and satellite navigation is mainly used at home and abroad, that is, integrated navigation. Developed countries, led by the United States, studied the combination of INS and GNSS earlier, and in the early 1990s, the United States and other countries had completed the combination of INS and GNSS, and achieved certain results. There are three existing modes, namely, loose combination, tight combination and deep combination. Through the study of psychology in higher education, college students can analyze the internal principles from the surface of things, guide them to realize the study of scientific and cultural knowledge, and thus provide the enthusiasm and interest in learning.

\section{The Relationship between College Students' Learning Characteristics and the Development of Robot Research}

The learning characteristics of college students are as follows. The first is the professional learning content of college students, which is manifested in the fol- 
lowing aspects: 1) clear career orientation; 2) The curriculum is designed to meet the needs of professional development; 3) Specialized practice ability training. The second is the autonomy of the learning process of college students. The independent learning of college students is mainly manifested in the following aspects: 1) initiative; 2) selectivity; 3) Criticism; 4) Exploratory. The third is the transcendence of college students' learning results. The transcendence of college students' learning results is mainly manifested in the following two aspects: 1) transcending the original learning situation; 2) Surpass the original self level. Because mechatronic engineering is the combination of computer hardware and software, machinery and electronics, components and systems, operation and manufacturing, set control science, computer technology, electronic technology, mechanical engineering as one of the comprehensive disciplines. The relationship between the learning characteristics of college students and the development of robot research is shown in Table 1. And in this direction, robot technology is very has the research value and application value of a technology, teachers can combine learning characters of college students' professional teaching, to introduce robot according to the characteristics of the first students learning content of professional, mechanical electronic engineering is a multidisciplinary cross discipline, There are control system, electromechanical system, visual perception, sensor technology and so on, and these technologies are exactly the core content of robot technology, so the introduction of robot research teaching has a professional learning content for college students majoring in mechanical and electronic engineering. The second characteristic for college students' autonomous learning process, because the learning of college students have initiative, selective, critical, and to explore the sex, how they are not interested in their learning content or thought for them without the value of learning, the learning autonomy of will be greatly reduced, and the robot technology is hot difficult problem in the future, Therefore, it can improve their learning autonomy. Third characteristics for college students learning results of transcendence, college students transcendence in beyond the original learning situations and beyond the original level of self, in learning a content, first of all to be able to find it, and puts forward some improvement opinions and ideas, robot technology

Table 1. The relationship between college students' learning characteristics and the development of robot research.

\begin{tabular}{|c|c|c|c|}
\hline \multirow{2}{*}{ number } & \multicolumn{3}{|c|}{$\begin{array}{l}\text { the relationship between college students' learning } \\
\text { characteristics and the development of robot research }\end{array}$} \\
\hline & $\begin{array}{l}\text { study characteristics } \\
\text { of college students }\end{array}$ & robotics research and development & reference source \\
\hline 1 & professional & the core of robotics & literature [9] \\
\hline 2 & autonomy & $\begin{array}{l}\text { the hot and difficult issues in the future } \\
\text { development of robot technology }\end{array}$ & literature [9] \\
\hline 3 & transcendence & $\begin{array}{l}\text { robotics that are immature and need to be } \\
\text { improved and developed }\end{array}$ & literature $[9]$ \\
\hline
\end{tabular}


is not yet mature, there are many areas in urgent need of improvement and research and development, thus can college students in the learning process, Discover the deficiency, and can try to improve, so as to promote the development and progress of technology.

\section{Conclusion}

Mechanical and electronic technology represented by robot technology has an important and extensive application in many fields such as military, civil and so on. How to better complete the teaching of mechanical and electronic major in the new era, combined with the current situation and trend of the development of science is very important. This article first analyses the core technology of the robot, find the robot technology in the teaching and scientific research combining site, and then the method of using higher education psychology, analyzes the study characteristics and psychological characteristics of college students, put forward to education into the robot application to the teaching of mechanical electronic engineering, can improve the students' learning purpose, enthusiasm, And for the future development of students to provide important knowledge reserves and scientific research methods of exercise, with a certain degree of practicality. This paper proposes a deep combination of robotics and mechatronics education, but the following aspects need to be further studied: 1) Specialty setting and the establishment of learning objectives; 2) Construction of professional curriculum system; 3) Construction of practice and training bases; 4) Integrated teaching staff construction.

\section{Conflicts of Interest}

The author declares no conflicts of interest.

\section{References}

[1] Wang, X. (2019) Development History of National College Student Robot Competition. Robot Technology and Application, 187, 30-32.

[2] Mueller, K., Fennel, M. and Trommer, G.F. (2020) Model Predictive Control for Vision-Based Quadrotor Guidance. 2020 IEEE/ION Position, Location and Navigation Symposium (PLANS), Portland, 20-23 April 2020, 50-61. https://doi.org/10.1109/PLANS46316.2020.9110137

[3] Martinez, P. and Barczyk, M. (2019) Implementation and Optimization of the Cascade Classifier Algorithm for UAV Detection and Tracking. Journal of Unmanned Vehicle Systems, 7, 296-311. https://doi.org/10.1139/juvs-2018-0033

[4] Zhang, S., Gong, Y.H. and Wang, J.J. (2019) Deep Convolutional Neural Network and Its Application in Computer Vision. Chinese Journal of Computers, 42, 453-482.

[5] Micheal, A.A., Vani, K., Sanjeevi, S., et al. (2021) Object Detection and Tracking with UAV Data Using Deep Learning. Journal of the Indian Society of Remote Sensing, 49, 463-469. https://doi.org/10.1007/s12524-020-01229-x

[6] Schonberger, J.L. and Frahm, J.M. (2016) Structure-from-Motion Revisited. Proceedings of the IEEE Conference on Computer Vision and Pattern Recognition, Las Vegas, 27-30 June 2016, 4104-4113. https://doi.org/10.1109/CVPR.2016.445 
[7] Yi, M. and Guo, B.L. (2012) Aerial Video Image Registration Method Based on Invariant Features and Mapping Restraint. Acta Aeronautica ET Astronautica Sinica, 33, 1872-1880.

[8] Li, W.Y., Wang, P. and Qiao, H. (2014) A Review of Target Tracking Methods with Visual Attention Mechanism. Acta Automatica Sinica, 40, 561-576.

[9] Zeng, X.J., Cai, D.B. and Wang, H.H. (2017) Research on Innovation Education Reform of Intelligent Robot Teaching Construction. Innovative Education Research, 5, 377-380. 